4-2012

\title{
BON-BONs: Cyclic Molecules with a Boron-Oxygen-Nitrogen Backbone. Computational Studies of Their Thermodynamic Properties
}

\author{
Aloysus K. Lawong \\ Cleveland State University \\ David W. Ball \\ Cleveland State University, d.ball@csuohio.edu
}

Follow this and additional works at: https://engagedscholarship.csuohio.edu/scichem_facpub

Part of the Physical Chemistry Commons

How does access to this work benefit you? Let us know!

Publisher's Statement

The final publication is available at Springer via http://dx.doi.org/10.1007/s00894-011-1193-2

\section{Recommended Citation}

Lawong, A. K.; Ball, D. W. BON-BONs: cyclic molecules with a boron-oxygen-nitrogen backbone. Computational studies of their thermodynamic properties. Journal of Molecular Modeling 2012, 18, 1661-1666.

This Article is brought to you for free and open access by the Chemistry Department at EngagedScholarship@CSU. It has been accepted for inclusion in Chemistry Faculty Publications by an authorized administrator of EngagedScholarship@CSU. For more information, please contact library.es@csuohio.edu. 


\title{
BON-BONs: cyclic molecules with a boron-oxygen-nitrogen backbone. Computational studies of their thermodynamic properties
}

\author{
Aloysus K. Lawong • David W. Ball
}

\begin{abstract}
Although they were first reported in 1963, molecules with a boron-oxygen-nitrogen dimeric backbone do not seem to have been investigated seriously in terms of thermodynamic properties. Here we report on the calculated structures and properties, including thermodynamics, of several so-called "BON-BON" molecules. With the popularity of nitrogen-containing substituents on new highenergy materials, nitro-substituted $\mathrm{BON}-\mathrm{BONs}$ were a focus of our investigation. A total of 42 BON-BON molecules were evaluated, and thermochemical analysis shows a decrease in the specific enthalpy of combustion or decomposition with increasing $\mathrm{NO}_{2}$ content, consistent with other systems.
\end{abstract}

Keywords B3LYP calculations - BON-BON molecules · High energy materials

\section{Introduction}

The search for new high energy (HE) materials is ongoing [1]. Good HE materials share certain physical characteristics, including high density, thermodynamics favorability of decomposition or combustion, and the production of high-pressure products upon reaction. Models for these characteristics, and others, have allowed researchers to probe the probabilities that new, as yet unsynthesized materials may be good potential HE targets.

A. K. Lawong $\cdot$ D. W. Ball $(\bowtie)$

Department of Chemistry, Cleveland State University,

2121 Euclid Avenue,

Cleveland, OH 44115, USA

e-mail: d.ball@csuohio.edu
Recently we have been interested [2-4] in boroncontaining compounds as potential HE materials because the formation of $\mathrm{B}_{2} \mathrm{O}_{3}$ as a decomposition/combustion product is very energetically favored; at $18.3 \mathrm{~kJ} \mathrm{~g}^{-1}$ [5], boron has one of the highest specific combustion energies of any element. For similar reasons, we have also investigated a series of boron/nitrogen compounds [6-8], taking advantage of the stability of $\mathrm{N}_{2}$ as a product of decomposition or combustion.

In 1963, Kuhn and Inatome [9] published a report on an air-stable boron-oxygen-nitrogen molecule that they determined was composed of a $\mathrm{BH}_{2}-\mathrm{O}-\mathrm{NH}_{2}$ dimer in which the nitrogen atom lone electron pair of one molecule was making a coordinate covalent bond with the empty $p$ orbital of the boron atom of the other molecule, forming a six-membered ring; they later presented experimental evidence, in the form of measured dipole moments, that the ring existed as a chair conformer [10]. Kuhn et al. referred to these molecules as "BONBON" species; unlike the original references, here we use all capital letters to emphasize the symbols of the elements in the six-membered ring. Kuhn et al.'s derivatives had several n-butyl groups bonded to either the boron atom or the nitrogen atom (or both) in the ring.

As far as we have been able to determine, thermodynamic properties of the BON-BON compounds have not been measured. We submit that the thermodynamic properties of these compounds may be intriguing, especially in regard to their enthalpies of combustion or decomposition. These molecules would be at least partially self-oxidizing, with $\mathrm{O}$ atoms in the ring, while at the same time forming stable $\mathrm{N}_{2}$ as a combustion or decomposition product. As such, we have conducted a systematic study of a series of molecules with a BON-BON central ring. Because nitro 
groups $\left(-\mathrm{NO}_{2}\right)$ are common in HE materials, [11] we have not only determined properties of the parent BON-BON molecule, but of BON-BON molecules containing up to eight $\mathrm{NO}_{2}$ groups.

\section{Computational details}

All calculations were performed using the Gaussian 09 computational chemistry program [12] on an IBM cluster 1350 supercomputer at the Ohio Supercomputer Center in Columbus, Ohio. The method used was the density functional theoretical method as defined using Becke's three-parameter exchange functional with the correlation functional of Lee, Yang, and Parr (abbreviated B3LYP in the Gaussian program) $[13,14]$ along with the standard Gaussian basis set labeled 6-31G(d,p) [15]. Minimumenergy geometries of the BON-BON molecules were determined using default settings, and vibrational frequency calculations were performed to verify that a minimumenergy geometry was found. Once the proper structure of the BON-BON molecule was established, the enthalpy of formation of was determined by calculating the enthalpy change for the molecule formed from its gaseous elements and then corrected for the enthalpy of formation of gasphase boron. For example, the reaction for the parent molecule was:

$$
\begin{aligned}
& 4 \mathrm{H}_{2}(\mathrm{~g})+\mathrm{O}_{2}(\mathrm{~g})+\mathrm{N}_{2}(\mathrm{~g})+2 \mathrm{~B}(\mathrm{~g}) \\
& \rightarrow \text { cyclo }-\mathrm{BH}_{2} \mathrm{ONH}_{2} \mathrm{BH}_{2} \mathrm{ONH}_{2}(\mathrm{~g}),
\end{aligned}
$$

whose energy change was determined from the calculations and then corrected for the formation of two moles of $\mathrm{B}(\mathrm{g})$ :

$$
2[\mathrm{~B}(\mathrm{~s}) \rightarrow \mathrm{B}(\mathrm{g})] \quad \Delta \mathrm{H}=2\left[565.0 \mathrm{~kJ} \mathrm{~mol}^{-1}\right] .
$$

The enthalpy of formation for $\mathrm{B}(\mathrm{g})$ was found at the NIST Chemistry Webbook website [5]. Once corrected for the formation of $\mathrm{B}(\mathrm{g})$, the energy represents the enthalpy of formation of the BON-BON molecule. After this, enthalpies of combustion and/or decomposition can be determined using standard balanced reactions, assuming that the products are $\mathrm{B}_{2} \mathrm{O}_{3}(\mathrm{~s}), \mathrm{H}_{2} \mathrm{O}(\ell)$, and $\mathrm{N}_{2}(\mathrm{~g})$, whose thermodynamic properties were also found at the NIST Chemistry Webbook [5]. When necessary, $\mathrm{O}_{2}(\mathrm{~g})$ is added as a reactant for complete oxidation of $\mathrm{B}$ and $\mathrm{H}$ in the molecules.

\section{Results and discussion}

In the course of our systematic study of BON-BON and its nitro derivatives, we explored all substitutional isomers and found a total of 42 isomers ranging from the parent molecule, cyclo- $\mathrm{BH}_{2} \mathrm{ONH}_{2} \mathrm{BH}_{2} \mathrm{ONH}_{2}$, to octanitro-BON$\mathrm{BON}$, cyclo- $\mathrm{B}\left(\mathrm{NO}_{2}\right)_{2} \mathrm{ON}\left(\mathrm{NO}_{2}\right)_{2} \mathrm{~B}\left(\mathrm{NO}_{2}\right)_{2} \mathrm{ON}\left(\mathrm{NO}_{2}\right)_{2}$. Further, we only explored positional isomers, not axial-vs.-equatorial isomers that may be possible for multiple $\mathrm{NO}_{2}$ groups (see below). Because of the sheer number of isomers in this study, in this report we will present specific data on only a few selected isomers and give complete results for all isomers only for thermodynamic data. Output files for all isomers are available upon request if additional analysis is desired.

Figure 1 shows the minimum-energy structures of the parent molecule, cyclo- $\mathrm{BH}_{2} \mathrm{ONH}_{2} \mathrm{BH}_{2} \mathrm{ONH}_{2}$; the symmetrically tetranitro-substituted cyclo- $\mathrm{B}\left(\mathrm{NO}_{2}\right) \mathrm{HON}\left(\mathrm{NO}_{2}\right)$ $\mathrm{HB}\left(\mathrm{NO}_{2}\right) \mathrm{HON}\left(\mathrm{NO}_{2}\right) \mathrm{H}$; and the octanitro-substituted cyclo$\mathrm{B}\left(\mathrm{NO}_{2}\right)_{2} \mathrm{ON}\left(\mathrm{NO}_{2}\right)_{2} \mathrm{~B}\left(\mathrm{NO}_{2}\right)_{2} \mathrm{ON}\left(\mathrm{NO}_{2}\right)_{2}$. We note that the BON-BON backbone shows the $\mathrm{N}$ atom making a
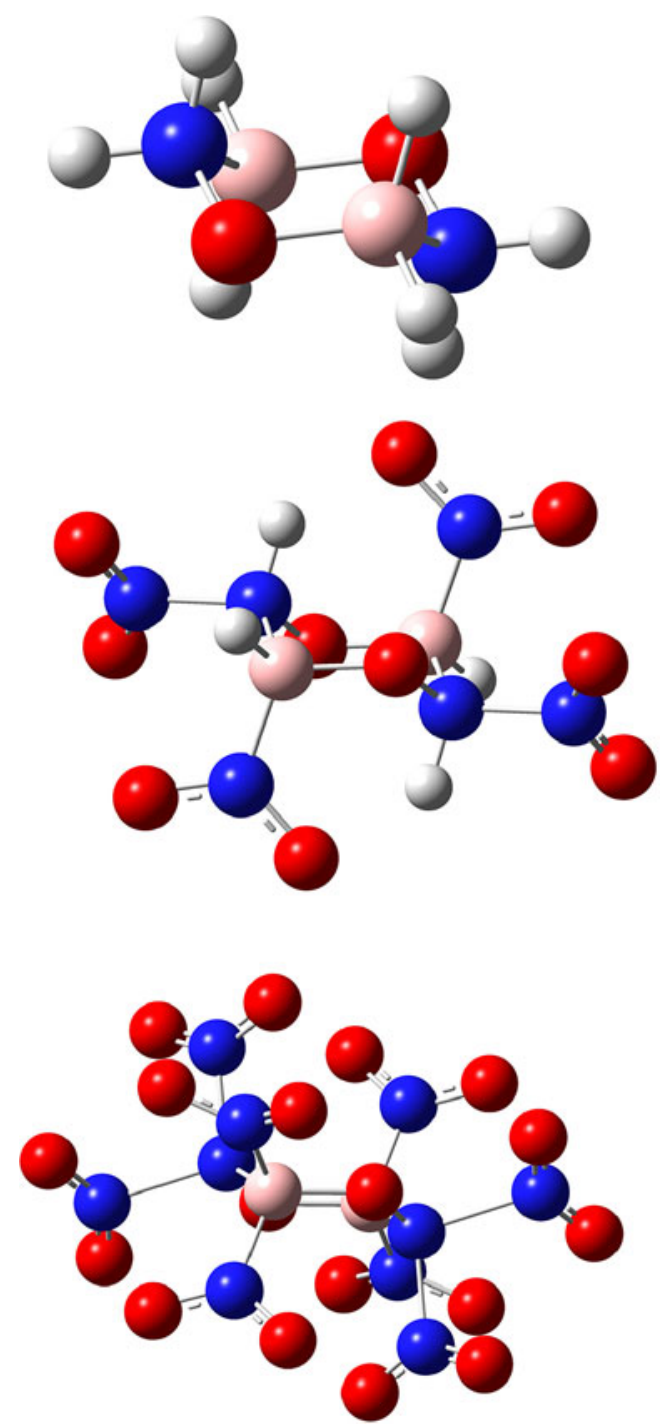

Fig. 1 Optimized structures of the parent BON-BON molecule, the symmetrically-substituted tetranitro-BON-BON, and octanitro-BON$\mathrm{BON}$. In the bottom molecule, the BON-BON central ring is almost obscured by the $\mathrm{NO}_{2}$ groups 
coordinate covalent bond to the $\mathrm{B}$ atom of the other $\mathrm{BON}$ moiety, and the six-membered ring is puckered, resembling the chair conformation of cyclohexane. It is this conformation of the BON-BON backbone that leads to the possibility of axial or equatorial positions for substitution, which is the stereoisomerism type we are ignoring here.

Table 1 lists representative bonding parameters of these three molecules; bonding parameters of the other substitutions and their isomers are intermediate between these. There are several trends worth discussing. First, upon successive nitration of the BON-BON ring, the sixmembered ring shrinks markedly (except for the B-O bond increasing $0.001 \AA$ going from the tetranitro-BON-BON to the octanitro-BON-BON). The six-membered ring opens up a bit, as seen by the B-O-N angle going from $109.6^{\circ}$ to $120.6^{\circ}$ and the N-B-O angle increasing from $105.7^{\circ}$ to $110.9^{\circ}$. The O-N-B bond angle, however, stays relatively constant from one extreme to the other, $111.9^{\circ}$ to $112.8^{\circ}$. This opening-up, however, is compensated for by a decrease in the ring pucker, measured by the boron atom in the ring being out of the central plane by $63.0^{\circ}$ for the parent BONBON but only $45.7^{\circ}$ for the octanitro-BON-BON.

Perhaps the most noteworthy bond parameter change relates to the bond to the $\mathrm{NO}_{2}$ group. The $\mathrm{B}-\mathrm{N}$ (nitro) bond distance stays relatively constant at around $1.56-1.56 \AA$. In N-nitro-BON-BON (not shown here), the N-N(nitro) bond optimized at $1.60 \AA$. In the tetranitro-BON-BON molecule (Fig. 1 and Table 1), the N-N(nitro) bond remains at about $1.60 \AA$. However, as the nitro content of the ring increases above four nitro groups, the N-N(nitro) bond increases, in some cases substantially. In the octanitro-BON-

Table 1 Selected bonding parameters of the parent BON-BON, tetranitro-BON-BON, and octanitro-BON-BON (see Fig. 1; $\mathrm{r}$ in $\AA$, angles in degrees)

\begin{tabular}{llll}
\hline BON-BON derivative & Parent & Tetranitro- & Octanitro- \\
\hline r(B-N) [ring] & 1.624 & 1.614 & 1.577 \\
r(N-O) [ring] & 1.429 & 1.399 & 1.351 \\
r(B-O) & 1.476 & 1.460 & 1.461 \\
r(B-H) & $1.205,1.214$ & 1.186 & - \\
r(N-H) & $1.020,1.028$ & 1.044 & - \\
r(B-N) [nitro] & - & 1.590 & $1.562,1.595$ \\
r(N-O) [nitro] & - & $1.189-1.249$ & $1.174-1.235$ \\
$r(\mathrm{~N}-\mathrm{N})$ & - & 1.605 & $1.696-1.899$ \\
$\alpha(\mathrm{B}-\mathrm{O}-\mathrm{N})$ & 109.6 & 112.8 & 120.6 \\
$\alpha(\mathrm{O}-\mathrm{N}-\mathrm{B})$ & 111.9 & 110.8 & 112.8 \\
$\alpha(\mathrm{N}-\mathrm{B}-\mathrm{O})$ & 105.7 & 105.5 & 110.9 \\
$\alpha(\mathrm{O}-\mathrm{B}-\mathrm{N})$ [nitro] & - & 112.1 & 108.6 \\
$\alpha(\mathrm{O}-\mathrm{N}-\mathrm{N})[$ [nitro] & - & $110.9,114.9$ & $107.2-113.5$ \\
$\alpha(\mathrm{O}-\mathrm{N}-\mathrm{O})$ [nitro] & - & $123.1,134.2$ & $124.3-140.6$ \\
Ring angle & 63 & 61.8 & 45.7 \\
\hline
\end{tabular}

BON, one of the N-N(nitro) bonds increases markedly to almost $1.90 \AA$, an unusually long bond distance for any type of covalent bond. The CRC Handbook [16] list mean N-N bond distances of $1.454 \AA$ for pyramidal-pyramidal N-N molecules (sample size $n=44$ ), $1.420 \AA$ for planar-pyramidal $\mathrm{N}-\mathrm{N}$ molecules $(n=68)$, and $1.401 \AA$ for planar-planar N-N molecules $(n=40)$. In octanitro-BON-BON, we have four pyramidal-planar N-N bonds, two being relatively short $(1.69 \AA)$ and two being relatively long $(1.89 \AA)$. Even the "relatively short" bond distance of $1.69 \AA$ is long for this type of N-N bond. Compare this with the N-N bond distances for some more simple compounds: $1.43 \AA$ for nitroamine, $\mathrm{NH}_{2} \mathrm{NO}_{2}$ [17; experimental value] but $1.52-$ $1.69 \AA$ for 1,1-dinitrohydrazine [18; computational]. Thus, while there is some evidence for long N-N bonds in nitro- $\mathrm{N}$ compounds, an N-N bond length of $1.89 \AA$ is extremely long for a covalent bond. However extreme, the trend seems unmistakable, as examination of the structures of the other derivatives demonstrates a slowly increasing N-N(nitro) bond distance, starting at $1.66 \AA$ for N-nitro-BON-BON (that is, the lone $\mathrm{NO}_{2}$ group is bonded to a nitrogen atom in the ring) and increasing as the number of nitro groups on the $\mathrm{N}$ atoms increase and as the nitro content of adjacent $\mathrm{B}$ and $\mathrm{N}$ atoms in the ring increases. The first effect is likely due to the electron-withdrawing nature of the $\mathrm{NO}_{2}$ group, decreasing the internuclear electron density between the two nitrogen atoms. The second circumstance can be explained the bulky $\mathrm{NO}_{2}$ group, as steric effects become important with nitro groups are bonded to adjacent $\mathrm{B}$ and $\mathrm{N}$ atoms in the ring.

The net effect suggests that the N-N(nitro) bond is the likely site for initiation of detonation or decomposition, a point already made by Murray et al. [19]. To support this, we estimated the N-N(nitro) bond energy by calculating the single-point energies of an $\mathrm{NO}_{2}$ fragment and the rest of the octanitro-BON-BON molecule, with both radicals having the same geometries as they have in the optimized octanitro-BON-BON molecule (i.e. vertical bond energies as opposed to adiabatic bond energies, the energy change as determined when the fragments are allowed to geometrically re-optimize). Ignoring energy contributions due to thermal energies and differing multiplicities, we calculated a $\Delta \mathrm{E}$ of $0.04685 \mathrm{~h}$, or $123.0 \mathrm{~kJ} \mathrm{~mol}^{-1}$. This is comparable to but less than the bond energy in elemental fluorine $(\mathrm{E}[\mathrm{F}-\mathrm{F}]=$ $158 \mathrm{~kJ} \mathrm{~mol}^{-1}$ ) and the $\mathrm{N}-\mathrm{NO}_{2}$ bond in methyl nitramine $\left(195 \mathrm{~kJ} \mathrm{~mol}^{-1}\right)$ and methyl dinitramine (185 $\mathrm{kJ} \mathrm{mol}^{-1}$; [19]), suggesting a stable but easily broken bond.

Table 2 lists the calculated enthalpies of formation, determined as described above, and the resulting enthalpies of combustion or decomposition for the various substitutional isomers of each level of nitration. In this table, the isomers are listed by the atom(s) that have a hydrogen atom substituted by a $\mathrm{NO}_{2}$ group. Any BON-BON molecule can 
Table 2 Oxygen balances, enthalpies of formation and combustion/decomposition, and specific enthalpies of reaction for BON-BON and its nitrated derivatives

\begin{tabular}{|c|c|c|c|c|}
\hline Compound & $\mathrm{OB} \%$ & $\Delta \mathrm{H}_{\mathrm{f}}, \mathrm{kJ} \mathrm{mol}^{-1}$ & $\Delta \mathrm{H}_{\mathrm{comb} / \mathrm{dec}}, \mathrm{kJ} \mathrm{mol}^{-1}$ & $\Delta \mathrm{H}_{\mathrm{comb} / \mathrm{dec}}, \mathrm{kJ} \mathrm{g}^{-1}$ \\
\hline $\mathrm{BH}_{2} \mathrm{ONH}_{2}-\mathrm{BH}_{2} \mathrm{ONH}_{2}$ & -89.3 & -313.1 & -1490.2 & -16.6 \\
\hline Nitro-BON-BON & -29.7 & & & \\
\hline B- & & -442.9 & -1239.4 & -9.21 \\
\hline $\mathrm{N}-$ & & -225.8 & -1456.6 & -10.8 \\
\hline Dinitro-BON-BON & 0 & & & \\
\hline B,B- & & -518.3 & -1043.2 & -5.81 \\
\hline $\mathrm{B}, \mathrm{B}^{\prime}-$ & & -517.8 & -1043.6 & -5.81 \\
\hline $\mathrm{B}, \mathrm{N}-$ & & -345.3 & -1216.2 & -6.77 \\
\hline $\mathrm{B}, \mathrm{N}^{\prime}-$ & & -336.8 & -1224.7 & -6.82 \\
\hline $\mathrm{N}, \mathrm{N}-$ & & -135.3 & -1426.1 & -7.94 \\
\hline $\mathrm{N}, \mathrm{N}^{\prime}-$ & & -126.9 & -1434.6 & -7.99 \\
\hline Trinitro-BON-BON & 17.8 & & & \\
\hline $\mathrm{B}, \mathrm{B}, \mathrm{B}^{\prime}-$ & & -607.1 & -833.5 & -3.71 \\
\hline $\mathrm{B}, \mathrm{B}, \mathrm{N}-$ & & -412.5 & -1028 & -4.58 \\
\hline $\mathrm{B}, \mathrm{B}, \mathrm{N}^{\prime}-$ & & -400.6 & -1039.9 & -4.63 \\
\hline $\mathrm{B}, \mathrm{N}, \mathrm{B}^{\prime}-$ & & -230.7 & -1209.8 & -5.39 \\
\hline $\mathrm{B}, \mathrm{N}, \mathrm{N}-$ & & -227.8 & -1212.7 & -5.4 \\
\hline $\mathrm{B}, \mathrm{N}, \mathrm{N}^{\prime}-$ & & -243.1 & -1197.4 & -5.33 \\
\hline $\mathrm{B}, \mathrm{N}^{\prime}, \mathrm{N}^{\prime}-$ & & -227.8 & -1212.7 & -5.4 \\
\hline $\mathrm{N}, \mathrm{N}, \mathrm{N}^{\prime}-$ & & -33.5 & -1407.1 & -6.26 \\
\hline Tetranitro-BON-BON & 29.7 & & & \\
\hline $\mathrm{B}, \mathrm{B}, \mathrm{B}^{\prime}, \mathrm{B}^{\prime}-$ & & -687.9 & -631.7 & -2.34 \\
\hline $\mathrm{B}, \mathrm{B}, \mathrm{B}^{\prime}, \mathrm{N}^{\prime}-$ & & -326.2 & -993.4 & -3.68 \\
\hline $\mathrm{B}, \mathrm{B}, \mathrm{N}, \mathrm{N}-$ & & -297.8 & -1021.8 & -3.79 \\
\hline $\mathrm{B}, \mathrm{N}, \mathrm{B}^{\prime}, \mathrm{B}^{\prime}-$ & & -475.9 & -843.7 & -3.13 \\
\hline $\mathrm{B}, \mathrm{N}, \mathrm{B}^{\prime}, \mathrm{N}^{\prime}-$ & & -341.5 & -978.2 & -3.63 \\
\hline $\mathrm{B}, \mathrm{N}, \mathrm{N}^{\prime}, \mathrm{N}^{\prime}-$ & & -495.3 & -824.3 & -3.06 \\
\hline $\mathrm{N}, \mathrm{N}, \mathrm{B}^{\prime}, \mathrm{N}^{\prime}-$ & & -130.8 & -1188.8 & -4.41 \\
\hline $\mathrm{N}, \mathrm{N}, \mathrm{N}^{\prime}, \mathrm{N}^{\prime}-$ & & 53.2 & -1372.8 & -5.09 \\
\hline Pentanitro-BON-BON & 38.1 & & & \\
\hline $\mathrm{B}, \mathrm{B}, \mathrm{N}, \mathrm{N}, \mathrm{B}^{\prime}-$ & & -386.6 & -812.1 & -2.58 \\
\hline $\mathrm{B}, \mathrm{B}, \mathrm{N}, \mathrm{B}^{\prime}, \mathrm{N}^{\prime}-$ & & -358.9 & -839.8 & -2.67 \\
\hline $\mathrm{B}, \mathrm{B}, \mathrm{N}, \mathrm{B}^{\prime}, \mathrm{B}^{\prime}-$ & & -555.9 & -642.8 & -2.04 \\
\hline $\mathrm{B}, \mathrm{B}, \mathrm{N}, \mathrm{N}, \mathrm{N}^{\prime}-$ & & -172.4 & -1026.3 & -3.26 \\
\hline $\mathrm{B}, \mathrm{B}, \mathrm{N}, \mathrm{N}^{\prime}, \mathrm{N}^{\prime}-$ & & -167.7 & -1031 & -3.28 \\
\hline $\mathrm{B}, \mathrm{B}, \mathrm{B}^{\prime}, \mathrm{N}^{\prime}, \mathrm{N}^{\prime}-$ & & -358.1 & -840.6 & -2.67 \\
\hline $\mathrm{B}, \mathrm{N}, \mathrm{N}, \mathrm{B}^{\prime}, \mathrm{N}^{\prime}-$ & & -233.2 & -965.5 & -3.07 \\
\hline $\mathrm{B}, \mathrm{N}, \mathrm{N}, \mathrm{N}^{\prime}, \mathrm{N}^{\prime}-$ & & 9.2 & -1207.9 & -3.84 \\
\hline Hexanitro-BON-BON & 44.5 & & & \\
\hline $\mathrm{B}, \mathrm{B}, \mathrm{N}, \mathrm{N}, \mathrm{B}^{\prime}, \mathrm{B}^{\prime}-$ & & -418.9 & -658.9 & -1.83 \\
\hline $\mathrm{B}, \mathrm{B}, \mathrm{N}, \mathrm{N}, \mathrm{B}^{\prime}, \mathrm{N}^{\prime}-$ & & -222.6 & -855.2 & -2.38 \\
\hline $\mathrm{B}, \mathrm{B}, \mathrm{N}, \mathrm{B}^{\prime} \mathrm{B}^{\prime} \mathrm{N}^{\prime}-$ & & -417.5 & -660.3 & -1.84 \\
\hline $\mathrm{B}, \mathrm{B}, \mathrm{N}, \mathrm{B}^{\prime}, \mathrm{N}^{\prime}, \mathrm{N}^{\prime}-$ & & -226.1 & -851.7 & -2.37 \\
\hline $\mathrm{B}, \mathrm{B}, \mathrm{N}, \mathrm{N}, \mathrm{N}^{\prime}, \mathrm{N}^{\prime}-$ & & -56.3 & -1021.4 & -2.84 \\
\hline $\mathrm{B}, \mathrm{N}, \mathrm{N}, \mathrm{B}^{\prime}, \mathrm{N}^{\prime}, \mathrm{N}^{\prime}-$ & & -49.7 & -1028.1 & -2.86 \\
\hline Heptanitro-BON-BON & 49.4 & & & \\
\hline $\mathrm{B}, \mathrm{B}, \mathrm{N}, \mathrm{N}, \mathrm{B}^{\prime}, \mathrm{B}^{\prime}, \mathrm{N}-$ & & -283.1 & -673.8 & -1.67 \\
\hline $\mathrm{B}, \mathrm{B}, \mathrm{N}, \mathrm{N}, \mathrm{B}^{\prime}, \mathrm{N}^{\prime}, \mathrm{N}^{\prime}-$ & & -112.1 & -844.8 & -2.09 \\
\hline Octanitro-BON-BON & 53.4 & -96.5 & -739.5 & -1.64 \\
\hline
\end{tabular}


be thought of as being composed of two BON units. Nitration in the initial BON unit is indicated with unprimed labels; if an isomer has $\mathrm{NO}_{2}$ groups on both $\mathrm{BON}$ units, the sites in the other BON half of the ring are indicated with primes (') on the label. The table also lists the oxygen balances $(\mathrm{OB} \%)$ of each level of nitration. For these compounds, the oxygen balance is given by the expression [20]:

$\mathrm{OB} \%=-\frac{3200\left(\frac{3}{4} b+\frac{1}{4} h+0 n-\frac{1}{2} o\right)}{\mathrm{MW}}$,

where $b, h, n$, and $o$ are the numbers of boron, hydrogen, nitrogen, and oxygen atoms in the molecular formulas, respectively, and MW is the molar mass of the molecule. $\mathrm{An} \mathrm{OB} \%$ that is negative indicates that a molecular formula does not have sufficient oxidizer (for these molecules, oxygen) present to completely oxidize all other atoms present, while an $\mathrm{OB} \%$ of zero or greater indicates that a molecular formula does contain sufficient oxidizer to completely oxidize all other atoms fully. Thus, substances with negative $\mathrm{OB} \%$ values need additional oxidizer (assumed here to be molecular oxygen) and the enthalpy changes of reaction with said oxidizer are appropriately labeled enthalpies of combustion $\left(\Delta \mathrm{H}_{\text {comb }}\right)$. Substances with zero or positive OB\% values have sufficient oxidizer to oxidize without the need for another reactant, so the enthalpy changes of reaction are more appropriately labeled enthalpies of decomposition $\left(\Delta \mathrm{H}_{\mathrm{dec}}\right)$. As the OB\% values in Table 2 demonstrate, only the parent BON-BON molecule and nitro-BONBON need additional oxygen to react, so the reaction enthalpies for those compounds are properly termed $\Delta \mathrm{H}_{\text {comb. }}$. For all other BON-BON derivatives, OB\% values are zero or positive, so the reaction enthalpies are properly termed $\triangle \mathrm{H}_{\mathrm{dec}}$.

The parent $\mathrm{BON}-\mathrm{BON}$, cyclo- $\mathrm{BH}_{2} \mathrm{ONH}_{2} \mathrm{BH}_{2} \mathrm{ONH}_{2}$, is calculated to have an enthalpy of formation of $-313 \mathrm{~kJ} \mathrm{~mol}^{-1}$ and a combustion enthalpy of $-1490 \mathrm{~kJ} \mathrm{~mol}^{-1}$. Because energy per unit mass is a useful concept for HE materials, this converts to $-16.6 \mathrm{~kJ} \mathrm{~g}^{-1}$ for the specific enthalpy of combustion for cyclo- $\mathrm{BH}_{2} \mathrm{ONH}_{2} \mathrm{BH}_{2} \mathrm{ONH}_{2}$. This is fairly high for an $\mathrm{HE}$ material; compare it to $-6.2 \mathrm{~kJ} \mathrm{~g}^{-1}$ for nitroglycerine and about $-5.0 \mathrm{~kJ} \mathrm{~g}^{-1}$ for both RDX and HMX. [11] However, each mole of cyclo- $\mathrm{BH}_{2} \mathrm{ONH}_{2} \mathrm{BH}_{2} \mathrm{ONH}_{2}$ requires $2.5 \mathrm{~mol}$ of $\mathrm{O}_{2}$ to oxidize fully, which at $\sim 80 \mathrm{~g}$ is almost as massive as the $1 \mathrm{~mol}$ of BON-BON. Still, the high value of its specific enthalpy of combustion makes cyclo$\mathrm{BH}_{2} \mathrm{ONH}_{2} \mathrm{BH}_{2} \mathrm{ONH}_{2}$ worth additional study.

There are two possible isomers of nitro-BON-BON, one with the nitro group attached to a $\mathrm{B}$ atom and one with the nitro group attached to an $\mathrm{N}$ atom. Table 2 shows the B- bonded nitro-BON-BON has an enthalpy of formation of $-443 \mathrm{~kJ} \mathrm{~mol}^{-1}$, while the N-bonded nitro-BON-BON has an enthalpy of formation of $-226 \mathrm{~kJ} \mathrm{~mol}^{-1}$. This simplest nitro derivative clearly demonstrates the trend that is also found in derivatives with higher levels of nitration: bonding an $\mathrm{NO}_{2}$ group to a $\mathrm{B}$ atom yields a molecule that is about $200 \mathrm{~kJ} \mathrm{~mol}^{-1}$ more stable than bonding an $\mathrm{NO}_{2}$ group to an $\mathrm{N}$ atom, all other things being the same.

Despite having strongly negative enthalpies of formation, the two nitro-BON-BON derivatives have large enthalpies of combustion and specific enthalpies of combustion. At -9 to $-10 \mathrm{~kJ}$ per gram, nitro-BON-BON has a specific energy density larger than most current HE materials.

The isomers of more highly nitrated BON-BON mirror the trend in enthalpies of formation when going from a $\mathrm{B}$ substituted BON-BON to an N-substituted BON-BON. In all cases, the isomers that have the most $\mathrm{B}-\mathrm{NO}_{2}$ groupings in the molecule are the most stable, while the ones having the most $\mathrm{N}-\mathrm{NO}_{2}$ groupings are the least stable. This trend reaches its extreme for tetranitro-BON-BON, for which the $\mathrm{B}, \mathrm{B}, \mathrm{B}^{\prime}, \mathrm{B}^{\prime}$-bonded isomer is over $700 \mathrm{~kJ} \mathrm{~mol}^{-1}$ more stable than the $\mathrm{N}, \mathrm{N}, \mathrm{N}^{\prime}, \mathrm{N}^{\prime}$-bonded isomer. (Indeed, this last isomer is one of the few nitro-BON-BON molecules that has a positive enthalpy of formation.) This difference also has an impact on the specific enthalpy of decomposition, as the B, $\mathrm{B}, \mathrm{B}^{\prime}, \mathrm{B}^{\prime}$-bonded isomer has less than half the energy per unit mass as the $\mathrm{N}, \mathrm{N}, \mathrm{N}^{\prime}, \mathrm{N}^{\prime}$-bonded isomer.

As the nitro content of the BON-BON molecule increases, the enthalpies of formation generally increase, although the exact value of $\Delta \mathrm{H}_{\mathrm{f}}$ depends strongly on how many $\mathrm{B}$ versus how many $\mathrm{N}$ sites are bonded to an $\mathrm{NO}_{2}$. Because of this, the enthalpies of combustion or decomposition generally increase as well. It may be tempting to report average enthalpies of combustion or decomposition for each level of nitration, but given the variability in $\mathrm{NO}_{2}$ sites in these molecules, we suggest that such an average would be misleading. One other obvious trend is that the specific enthalpy of combustion or decomposition, in units of energy per unit mass, decreases significantly as the level of nitration increases. While nitro-BON-BON has a specific enthalpy of combustion of around $-10 \mathrm{~kJ} \mathrm{~g}^{-1}$, this value drops to about one sixth of this value for octanitro-BONBON. The molar enthalpy of decomposition does not decrease its magnitude as much, although there is a noticeable trend of such as the level of nitration increases. However, the relatively large mass of a $\mathrm{NO}_{2}$ group (46 u) means that the energy change per unit gram drops faster than energy change per unit mole. This is similar to trends we have noted for other compounds having low to high $\mathrm{NO}_{2}$ content $[18,21-23]$. 
In summary, our results show that while the parent BONBON compound or low-nitrated BON-BON compounds have energy densities that rival current $\mathrm{HE}$ materials, BONBON compounds of higher $\mathrm{NO}_{2}$ content have significantly lower specific enthalpies of decomposition. Of course, a good HE material must have other desirable characteristics, but it seems unlikely that a compound giving off low energy per unit mass would be a viable target for additional studies.

Acknowledgments We would like to thank the Ohio Supercomputer Center in Columbus, $\mathrm{OH}$, for a grant of time to perform this work. AKL thanks the McNair Scholars Program at Cleveland State University for support.

\section{References}

1. Badgujar DM, Talawar MB, Asthana SN, Mahulikar PP (2008) J Hazard Mater 151:289-305

2. Richard RM, Ball DW (2007) J Mol Struct THEOCHEM 814:91-98

3. Hillegass J Jr, Ball DW (2007) J Undergrad Chem Res 6:178-185

4. Richard RM, Ball DW (2008) J Mol Struct THEOCHEM 851:284-293

5. NIST Chemistry Webbook. http:// webbooknistgov. Accessed 20 April 2011

6. Richard RM, Ball DW (2008) J Mol Model 14:871-878
7. Richard RM, Ball DW (2007) J Mol Struct THEOCHEM 823:615

8. Tricamo AJ, Knaus KJ, Ball DW (2007) J Mol Struct THEOCHEM 807:67-72

9. Kuhn LP, Inatome N (1963) J Am Chem Soc 85:12061207

10. Thomson HB, Kuhn LP, Inatome N (1964) J Phys Chem 68:421422

11. Akhavan J (2004) The Chemistry of Explosives 2nd edition. Royal Society of Chemistry, London

12. Frisch MJ, Trucks GW, Schlegel HB et al (2009) Gaussian 09, Revision A01. Gaussian Inc, Wallingford, CT

13. Becke AD (1993) J Chem Phys 98:5648-5652

14. Lee C, Yang W, Parr RG (1988) Phys Rev 37:785-789

15. Hariharan PC, Pople JA (1973) Theor Chem Acc 28:213222

16. Lide DR (ed) (2008) CRC Handbook of Chemistry and Physics, 89th edn. CRC Press, Boca Raton, FL

17. Tyler JK (1963) J Mol Spectrosc 11:39-46

18. Ball DW (2006) J Mol Struct THEOCHEM 773:1-7

19. Murray JS, Concha MC, Politzer P (2009) Mol Phys 107:8997

20. Persson PA, Holmberg R, Lee J (1993) Rock Blasting and Explosives Engineering. CRC Press, Boca Raton, FL

21. Richard RM, Ball DW (2008) J Mol Struct THEOCHEM 858:8587

22. Lawong AK, Ball DW (2009) J Mol Struct THEOCHEM 916:3336

23. Wagner RR, Ball DW (2011) J Mol Model. 2011 Feb 12 (Epub ahead of print) 